\title{
The Dry Etching Properties of TaN Thin Film Using Inductively Coupled Plasma
}

\author{
Jong-Chang Woo, Young-Hee Joo, and Chang-II Kim ${ }^{+}$ \\ School of Electrical and Electronics Engineering, Chung-Ang University, Seoul 156-756, Korea
}

Received July 7, 2012 Revised September 6, 2012; Accepted September 6, 2012

\begin{abstract}
We investigated the etching characteristics of TaN thin films in an $\mathrm{O}_{2} / \mathrm{BCl}_{3} / \mathrm{Cl}_{2} / \mathrm{Ar}$ gas using a high density plasma (HDP) system. A maximum etch rate of the TaN thin films and the selectivity of TaN to $\mathrm{SiO}_{2}$ were obtained as 172.7 $\mathrm{nm} / \mathrm{min}$ and 6.27 in the $\mathrm{O}_{2} / \mathrm{BCl}_{3} / \mathrm{Cl}_{2} / \mathrm{Ar}$ (3:2:18:10 sccm) gas mixture, respectively. At the same time, the etch rate was measured as a function of the etching parameters, such as the RF power, DC-bias voltage, and process pressure. The chemical states on the surface of the etched TaN thin films were investigated using X-ray photoelectron spectroscopy. Auger electron spectroscopy was used for elemental analysis on the surface of the etched TaN thin films. These surface analyses confirm that the surface of the etched TaN thin film is formed with the nonvolatile by-product.
\end{abstract}

Keywords: Etch, XPS, AES, TaN, ICP

\section{INTRODUCTION}

As the critical dimensions of the metal-oxide semiconductor field-effect transistor shrank for the $45 \mathrm{~nm}$ node and those below, the scaling down of $\mathrm{SiO}_{2}$ thickness has exacerbated the problems such as increased leakage current, poly-Si gate depletion, and boron penetration into the channel region $[1,2]$. To overcome these problems, the conventional poly-Si gates on ultrathin $\mathrm{SiO}_{2}$ dielectric layers could be replaced by metal gates on high$k$ dielectric materials. Metal electrode/high- $k$ gate stacks have already been implemented. However, it requires continuous improvement with scaling. Currently, to integrate Hf-based high$k$ dielectric materials the use of various metal gate electrode materials including TaN and TiN have been widely studied [3-6]. The TaN thin film is very attractive because of its high thermal stability, good adhesion to substrate, high melting point, and low resistivity [7-12]. In order to pattern the metal electrode/high$k$ gate stack structure, etching of the metal electrode against a high- $k$ dielectric layer can be employed. Therefore, the higher

${ }^{\dagger}$ Author to whom all correspondence should be addressed:

E-mail: cikim@cau.ac.kr

Copyright $@ 2012$ KIEEME. All rights reserved.

This is an open-access article distributed under the terms of the Creative Commons Attribution Non-Commercia



etch rate and the higher selectivity of the metal gate electrode to the high- $k$ dielectric are required because of the very thin nature of high- $k$ dielectric materials. Also, we added $\mathrm{O}_{2}$ gas for the passivation layer formation on the sidewall and the improved selectivity of the metal gate dielectric [13].

In this work, we investigated the etch characteristics of TaN thin films using an inductively coupled plasma (ICP) system. The etching characteristics of the TaN thin film were investigated in terms of the selectivity of $\mathrm{TaN}$ to $\mathrm{SiO}_{2}$ as a function of Cl-based gas chemistry. The chemical states on the surface of the etched TaN thin film were investigated by X-ray photoelectron spectroscopy (XPS). Auger electron spectroscopy (AES) was used for the elemental analysis on the surfaces of the etched TaN thin film.

\section{EXPERIMENTAL}

The TaN thin films were deposited on $\mathrm{SiO}_{2} / \mathrm{Si}$ 6-in p-type (100) wafers by the atomic layer deposition (ALD) system. Before the deposition of the TaN thin films, pre-cleaning and oxidation processes for the Si wafer were required to obtain good thermal interface compatibility with the TaN thin film, which was deposited on the $\mathrm{SiO}_{2}(100 \mathrm{~nm}) / \mathrm{Si}(100)$ by ALD with a thickness of $100 \mathrm{~nm}$. The dry etching of the TaN thin films was performed using an ICP system [14]. A $13.56 \mathrm{MHz}$ power generator was connected to a 3.5 turn copper coil to generate the ICP. Another $13.56 \mathrm{MHz}$ power 




Fig. 1. Inductively coupled plasma system.



Fig. 2. Etch rate of TaN thin films and the selectivity of $\mathrm{TaN}$ to $\mathrm{SiO}_{2}$ as a function of the $\mathrm{O}_{2} / \mathrm{BCl}_{3} / \mathrm{Cl}_{2} / \mathrm{Ar}$ gas mixing ratio.

generator was attached to the substrate electrode to control the DC-bias voltage. The substrate temperature was kept at $40^{\circ} \mathrm{C}$ with a water cooling system. The chamber was pumped to $10^{-4} \mathrm{~Pa}$. The final pressure was lower than $10^{-4} \mathrm{~Pa}$ with a turbo-molecular pump. The etching characteristics of the TaN thin films were investigated as a function of the $\mathrm{O}_{2} / \mathrm{BCl}_{3} / \mathrm{Cl}_{2} / \mathrm{Ar}$ gas mixing ratio. The etching conditions of the RF power, DC-bias voltage, and process pressure were $500 \mathrm{~W},-100 \mathrm{~V}$, and $1 \mathrm{~Pa}$, respectively. The etch rates were measured using a depth profiler (Alpha-Step 500, KLA-Tencor). AES analyses were performed with a scanning auger microprobe (Microlab 350, VG Scientific, primary electron beam energy: $10 \mathrm{keV}$, beam current: $10 \mathrm{nA}$ ). The $4 \mathrm{keV} \mathrm{Ar}^{+}$ions were used for depth profile measurements. The composition change on the surface of the etched TaN thin film was analyzed by XPS The XPS spectra were collected using a VG Scientific ESCALAB 250 instrument equipped with an analytical chamber. The chamber was pumped down to a base pressure of less than $10^{-8} \mathrm{~Pa}$ with a twin-anode $x$-ray source, and a spherical sector analyzer with multichannel detectors. The samples were mounted on stainless steel stubs using double-sided adhesive tape, and $\mathrm{Al} K \alpha$ radiation ( $h v=1,486.6 \mathrm{eV}$ ) was used as an X-ray source. All XPS data were corrected for sample charging during $\mathrm{X}$-ray irradiation using an adventitious hydrocarbon referencing peak (C $1 \mathrm{~s}$ at $284.6 \mathrm{eV}$ ).

\section{RESULTS AND DISCUSSION}

\subsection{Etching Parameters}

To evaluate the etch characteristics of the TaN thin films in an
Table 1. List of Gibb's free energy of formation, $\Delta \mathrm{G}^{\circ} \mathrm{f}$ for the formation of etch by-products.

\begin{tabular}{cccc}
\hline \multicolumn{2}{c}{ Volatile etch products } & \multicolumn{2}{c}{ Nonvolatile etch products } \\
\hline Reaction & $\Delta \mathrm{G}_{\mathrm{f}}^{\circ}(\mathrm{kJ} / \mathrm{mol})$ & Reaction & $\Delta \mathrm{G}_{\mathrm{f}}^{\circ}(\mathrm{kJ} / \mathrm{mol})$ \\
\hline \hline $\mathrm{TaCl}_{2}(\mathrm{~g})$ & -77.011 & $\mathrm{TaO}_{2} \mathrm{Cl}(\mathrm{s})$ & -968.390 \\
\hline $\mathrm{TaCl}_{3}(\mathrm{~g})$ & -313.170 & $\mathrm{TaO}_{2} \mathrm{Cl}_{3}(\mathrm{~s})$ & -802.599 \\
\hline $\mathrm{TaCl}_{4}(\mathrm{~g})$ & -540.657 & $\mathrm{TaCl}_{3}(\mathrm{~s})$ & -480.010 \\
\hline $\mathrm{TaCl}_{5}(\mathrm{~g})$ & -709.287 & $\mathrm{TaCl}_{4}(\mathrm{~s})$ & -613.663 \\
\hline & & $\mathrm{TaCl}_{5}(\mathrm{~s})$ & -746.410 \\
\hline
\end{tabular}

Table 2. Melting and boiling points of etch by-products at $1 \mathrm{~atm}$.

\begin{tabular}{ccc}
\hline Compounds & Melting Point $\left({ }^{\circ} \mathrm{C}\right)$ & Boiling Point $\left({ }^{\circ} \mathrm{C}\right)$ \\
\hline $\mathrm{Ta}$ & 3,007 & 5,458 \\
\hline $\mathrm{TaN}$ & 3,090 & - \\
\hline $\mathrm{TaCl}_{5}$ & 216 & 239 \\
\hline
\end{tabular}

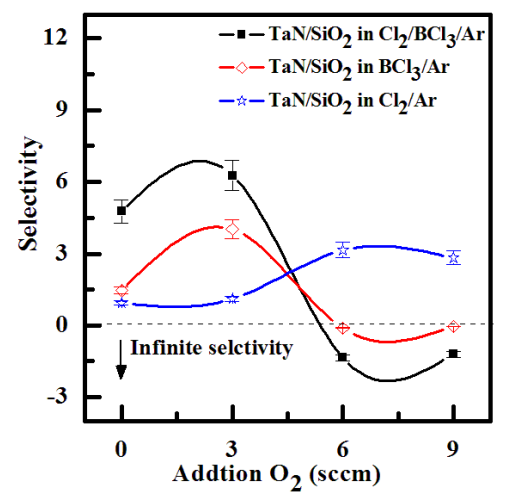

Fig. 3. Etch rate of TaN thin films and the selectivity of TaN to $\mathrm{SiO}_{2}$ as a function of the RF power.

ICP etching system, the TaN thin films were etched by varying the $\mathrm{BCl}_{3} / \mathrm{Ar}, \mathrm{Cl}_{2} / \mathrm{Ar}$, and $\mathrm{BCl}_{3} / \mathrm{Cl}_{2} / \mathrm{Ar}$ gas chemistry. Figure 2 presents (a) the etch rates of TaN thin film and (b) the selectivity of TaN to $\mathrm{SiO}_{2}$ as a function of $\mathrm{O}_{2}$ content in the $\mathrm{Cl}_{2} / \mathrm{Ar}, \mathrm{BCl}_{3} / \mathrm{Ar}$, and $\mathrm{BCl}_{3} / \mathrm{Cl}_{2} / \mathrm{Ar}$ gas mixture. The other conditions of the $\mathrm{RF}$ power, DC-bias voltage, and process pressure were kept at $500 \mathrm{~W},-100$ $\mathrm{V}$, and $1 \mathrm{~Pa}$, respectively. The maximum etch rate of the TaN thin film and the selectivity of TaN to $\mathrm{SiO}_{2}$ were $172.7 \mathrm{~nm} / \mathrm{min}$ and 6.27 in the $\mathrm{O}_{2} / \mathrm{BCl}_{3} / \mathrm{Cl}_{2} / \mathrm{Ar}$ (=3:2:18:10) gas mixture, respectively. As the $\mathrm{O}_{2}$ concentration increased from 0 to $3 \mathrm{sccm}$, the etch rate of the TaN thin films and the selectivity of $\mathrm{TaN}$ to $\mathrm{SiO}_{2}$ increased from 155.35 to $172.7 \mathrm{~nm} / \mathrm{min}$ and from 4.7 to 6.27 , respectively. But, when the $\mathrm{O}_{2}$ concentration increased over $3 \mathrm{sccm}$, the etch rate of the TaN thin films and the selectivity of TaN to $\mathrm{SiO}_{2}$ decreased from 172.7 to $144.7 \mathrm{~nm} / \mathrm{min}$ and from 6.27 to -1.2 , respectively. Table 1 shows the Gibb's free energy of etch products, and Table 2 shows the melting and, boiling point. In our opinion, the domination of the chemical reactions can be explained by the following factors. A) The melting point of $\mathrm{TaCl}_{5}$ is approximately $216^{\circ} \mathrm{C}$, the domination of the chemical pathway may be related to its lack of volatility, by contrast, the melting point of the $\mathrm{Ta}-\mathrm{Cl}_{5}$ is lower than the melting point of the Ta-N $\left(=3,090^{\circ} \mathrm{C}\right)$. B) The Ta-Cl chemical bond $(\mathrm{kJ} / \mathrm{mol})$ has a lower Gibb's free energy. The decrease of chemical bonds was due to the decreasing density of $\mathrm{Cl}$ radicals because the $\mathrm{Cl}$ atoms formed in the plasma react with TaN spontaneously [15-17].

Figure 3 illustrates the etch rates of TaN thin film and the selectivity of TaN to $\mathrm{SiO}_{2}$ as a function of the RF power in the $\mathrm{O}_{2} / \mathrm{BCl}_{3} /$ 


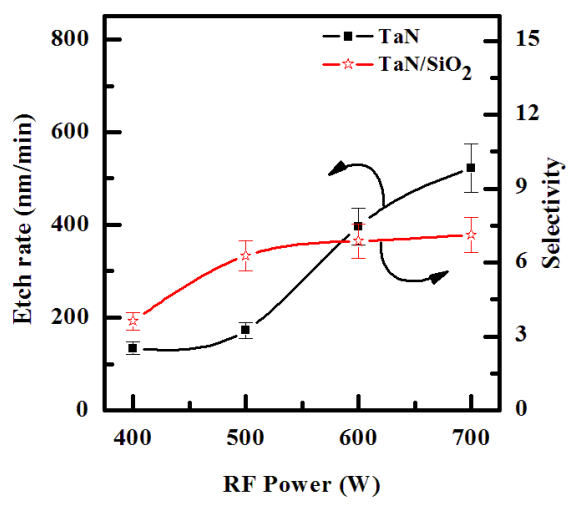

Fig. 4. Etch rate of TaN thin films and the selectivity of $\mathrm{TaN}$ to $\mathrm{SiO}_{2}$ as a function of the DC-bias voltage.

$\mathrm{Cl}_{2} / \mathrm{Ar}$ (3:2:18:10 sccm) plasma. The other conditions of the DCbias voltage, and process pressure were $-100 \mathrm{~V}$ and $1 \mathrm{~Pa}$, respectively. As the RF power increased from 400 to $600 \mathrm{~W}$, the etch rate of TaN thin film increased from $134.15 \mathrm{~nm} / \mathrm{min}$ to $521.91 \mathrm{~nm} /$ min, and the selectivity of TaN to $\mathrm{SiO}_{2}$ increased from 3.63 to 6.87 . Below $700 \mathrm{~W}$, the results show the enhancements of the oxidation of metal nitrides, as shown in Table 1 . Above $700 \mathrm{~W}$, the results show the re-deposition of metal-oxygen-chlorine by-products that can be more stable than metal-chlorine by-products [18]. An increase in the RF power causes monotonic increases in both the dissociation and the ionization rates, and thus in the densities and fluxes of the $\mathrm{O}$ and $\mathrm{Cl}$ atoms and positive ions. In our case, such a layer can be resulted from both the deposition of solid $B$, which may bond with the surface oxygen to form $\mathrm{B}_{\mathrm{x}} \mathrm{O}_{\mathrm{y}}$, and the $\mathrm{B}$ and $\mathrm{Cl}$ radicals incorporated in the polymer-like structure [19].

Figure 4 shows the etch rate of the TaN thin film as a function of the DC-bias voltage in the $\mathrm{O}_{2} / \mathrm{BCl}_{3} / \mathrm{Cl}_{2} / \mathrm{Ar}(3: 2: 18: 10 \mathrm{sccm})$ plasma. As the DC-bias voltage increases from - 50 to - $200 \mathrm{~V}$, the etch rates of the TaN thin films increase from 72.63 to $581.93 \mathrm{~nm} /$ $\mathrm{min}$. The increase in the etch rate is attributed to the increase of the mean ion energy, resulting in an increase in the sputtering yields for both TaN and the reaction products. These results can probably be explained by the higher binding energy of the Si-O (799 kJ/mol) bond than that of the Ta-N $(611 \mathrm{~kJ} / \mathrm{mol})$ bond [10].

Figure 5 shows the etch rate of TaN thin film as a function of the process pressure in the $\mathrm{O}_{2} / \mathrm{BCl}_{3} / \mathrm{Cl}_{2} / \mathrm{Ar}(3: 2: 18: 10 \mathrm{sccm})$ plasma. As the process pressures increased from 0.5 to $2.0 \mathrm{~Pa}$, the etch rates of TaN thin film decreased from 223.7 to $147.6 \mathrm{~nm} /$ min, respectively. The decrease of the process pressure enhances the density of the chemically neutral active species, which accelerates the chemical reaction [20]. Also, since the mean free path and energy of the ions increase with decreasing process pressure, the ion stimulated desorption of the reaction products is increased and the fraction of free surface available for the chemical reaction is increased. As a result of the pressure effect on the etch rate of the TaN thin film, the etch process is limited by the supply of the chemical source and, thus, the etch rate of TaN thin film increases with decreasing process pressure.

\subsection{Surface analysis}

To analyze the chemical states on the surface of the etched TaN thin films exposed to the $\mathrm{BCl}_{3} / \mathrm{Cl}_{2} / \mathrm{Ar}(2: 18: 10 \mathrm{sccm})$ and $\mathrm{O}_{2} / \mathrm{BCl}_{3} / \mathrm{Cl}_{2} / \mathrm{Ar}$ (3:2:18:10 sccm) plasmas, the samples were investigated by XPS and AES. The input plasma parameters were set to an RF power of $500 \mathrm{~W}$, DC-bias voltage of - $100 \mathrm{~V}$, process pressure of $1 \mathrm{~Pa}$ and substrate temperature of $40^{\circ} \mathrm{C}$. No boron



Fig. 5. Etch rate of TaN thin films and the selectivity of TaN to $\mathrm{SiO}_{2}$ as a function of the process pressure.
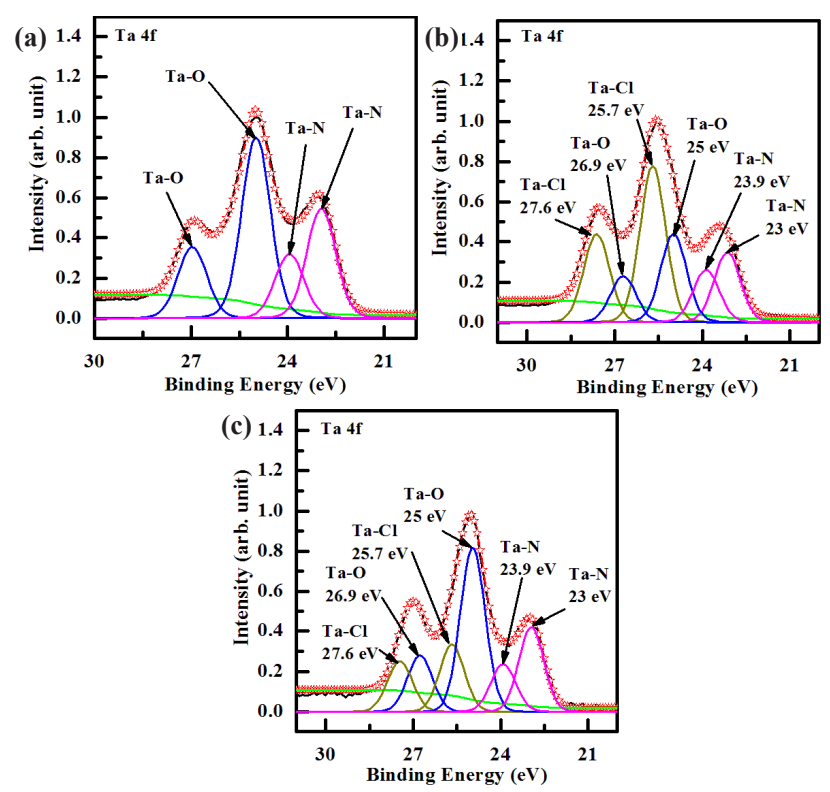

Fig. 6. Ta $4 \mathrm{f}$ XPS narrow spectra on the surface as a function of the etch chemistry (a) As-deposited, (b) $\mathrm{BCl}_{3} / \mathrm{Cl}_{2} / \mathrm{Ar}$ plasma, and (c) $\mathrm{O}_{2} /$ $\mathrm{BCl}_{3} / \mathrm{Cl}_{2} /$ Ar plasma.

peaks were detected. This means that the boron and chlorine compounds are highly volatile ones such as boron-oxy-chloride (BOCl) or trichloro-boroxin $(\mathrm{BOCl})_{3}[21]$.

Figure 6 shows the deconvoluted peaks of the Ta $4 \mathrm{f}$ XPS narrow scan spectra for (a) the as-deposited films and the surface of the etched TaN thin films in (b) the $\mathrm{BCl}_{3} / \mathrm{Cl}_{2} / \mathrm{Ar}$ and (c) $\mathrm{O}_{2} /$ $\mathrm{BCl}_{3} / \mathrm{Cl}_{2} / \mathrm{Ar}$ plasma, respectively. Figure 6 (a) shows the Ta $4 \mathrm{f}$ peak from the as-deposited TaN thin film which must originate from Ta-O and Ta-N bonds. It can be seen that the Ta $4 \mathrm{f}$ peak can be deconvoluted into four peaks, viz. Ta-O $(25,26.9 \mathrm{eV})$ and Ta-N (23, $24.9 \mathrm{eV}$ ). As shown in Fig. 6(b) and (c), it can be seen that when the TaN thin films were exposed to both the $\mathrm{BCl}_{3} / \mathrm{Cl}_{2} / \mathrm{Ar}(2: 18: 10$ sccm) plasma and $\mathrm{O}_{2} / \mathrm{BCl}_{3} / \mathrm{Cl}_{2} / \mathrm{Ar}(3: 2: 18: 10 \mathrm{sccm})$ plasma, the new peaks of Ta-Cl bonds appeared at $25.7 \mathrm{eV}$, and $27.6 \mathrm{eV}$ which were higher binding energies by about $\pm 0.7 \mathrm{eV}$. Figure 6 (a) and (b) can be deconvoluted into six peaks from the etched sample. When adding $\mathrm{O}_{2}$ in $\mathrm{BCl}_{3} / \mathrm{Cl}_{2} / \mathrm{Ar}$ plasma, the intensity of Ta-Cl bonds decreased and the intensity of Ta- $\mathrm{N}$ bonds increased [22]. The XPS data provides clear confirmation that etching of the TaN thin film in the $\mathrm{O}_{2} / \mathrm{BCl}_{3} / \mathrm{Cl}_{2} / \mathrm{Ar}$ plasma results in the formation of 

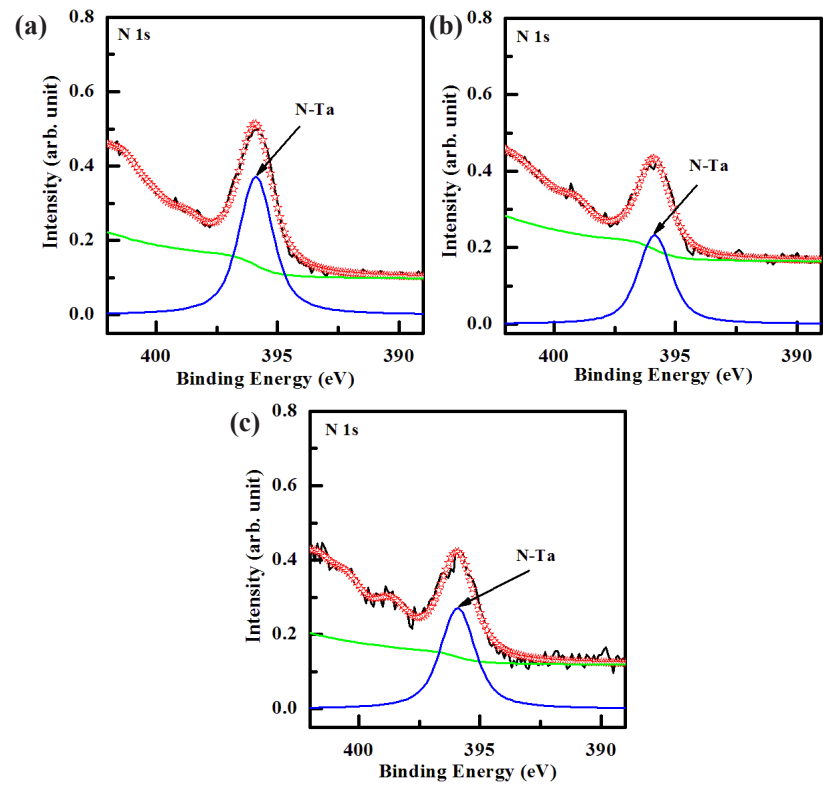

Fig. 7. N 1s XPS narrow spectra on the surface as a function of the etch chemistry (a) As-deposited, (b) $\mathrm{BCl}_{3} / \mathrm{Cl}_{2} / \mathrm{Ar}$ plasma, and (c) $\mathrm{O}_{2} /$ $\mathrm{BCl}_{3} / \mathrm{Cl}_{2} / \mathrm{Ar}$ plasma.

Ta-Ox bonds on its surface. Thus, the etch rate of TaN thin films was decreased when the $\mathrm{O}_{2}$ concentration increased over $3 \mathrm{sccm}$.

Figure 7 shows the deconvoluted peaks of the N 1s XPS narrow scan spectra for (a) the as-deposited films and the surface of the etched TaN thin films in (b) the $\mathrm{BCl}_{3} / \mathrm{Cl}_{2} / \mathrm{Ar}$ and (c) $\mathrm{O}_{2} / \mathrm{BCl}_{3} /$ $\mathrm{Cl}_{2} / \mathrm{Ar}$ plasma, respectively. For the $\mathrm{N}$ 1s peak, the peak at 395.9 $\mathrm{eV}$ corresponded to that of N-Ta, which originated from the interface of the TaN thin film. As shown in Fig. 7 (b) and (c), the shoulder peaks of $\mathrm{N}-\mathrm{Ta}(395.9 \mathrm{eV})$ was decreased significantly in the $\mathrm{BCl}_{3} / \mathrm{Cl}_{2} / \mathrm{Ar}$ and $\mathrm{O}_{2} / \mathrm{BCl}_{3} / \mathrm{Cl}_{2} / \mathrm{Ar}$ plasma as a result of the preferential removal of $\mathrm{Ta}$ and $\mathrm{N}$. However, when the TaN thin films were etched in the $\mathrm{BCl}_{3} / \mathrm{Cl}_{2} / \mathrm{Ar}$ and $\mathrm{O}_{2} / \mathrm{BCl}_{3} / \mathrm{Cl}_{2} / \mathrm{Ar}$ plasma, the $\mathrm{N}$ 1s peak intensity at $395.9 \mathrm{eV}$ was decreased due to the formation of Cl-N bonds [23]. The intensity of the $\mathrm{N}$ 1s peck for the surface of the etched TaN thin film in $\mathrm{O}_{2} / \mathrm{BCl}_{3} / \mathrm{Cl}_{2} / \mathrm{Ar}$ plasma was higher than that of the etched TaN thin film in the $\mathrm{BCl}_{3} / \mathrm{Cl}_{2} / \mathrm{Ar}$ plasma. This is due to the dramatic increase in the number of $\mathrm{Cl}-\mathrm{N}$ bonds, which resulted from the effective dissociation of the Ta-N bonds by the ion bombardment. Based on the XPS result, it was revealed that Ta and $\mathrm{N}$ were removed by the chemical reactions with the $\mathrm{Cl}$ radicals and the physical bombardment of the Ar ions [24-26].

Figure 8 shows the AES surface scan spectra of the TaN thin film for (a) the as-deposited films and the surface of the etched TaN thin films in (b) the $\mathrm{BCl}_{3} / \mathrm{Cl}_{2} / \mathrm{Ar}$ and (c) $\mathrm{O}_{2} / \mathrm{BCl}_{3} / \mathrm{Cl}_{2} / \mathrm{Ar}$ plasma, respectively. The etching time of the TaN thin film was 10 sec. Figure 8(a) shows an AES surface scan of the as-deposited TaN thin film in which $\mathrm{O}$ peaks are detected. The origin of carbon elements are a result of the contamination in the etching chamber or the air. After etching, the B and Cl-related peaks were not observed. With the addition of $\mathrm{O}_{2}$ gas, the intensity of $\mathrm{N}$ peaks increased compared to that of the etched sample in $\mathrm{BCl}_{3}$ / $\mathrm{Cl}_{2} / \mathrm{Ar}$ plasma. This result means that by-products such as Ta-O increased on the etched surface in $\mathrm{O}_{2} / \mathrm{BCl}_{3} / \mathrm{Cl}_{2} / \mathrm{Ar}$ plasma. Therefore, the XPS and AES data clearly show that the surface of the etched TaN thin films in $\mathrm{O}_{2} / \mathrm{BCl}_{3} / \mathrm{Cl}_{2} / \mathrm{Ar}$ plasma is formed with nonvolatile etch products such as Ta- $\mathrm{O}_{\mathrm{x}}$ and $\mathrm{Ta}-\mathrm{Cl}_{\mathrm{x}}$.
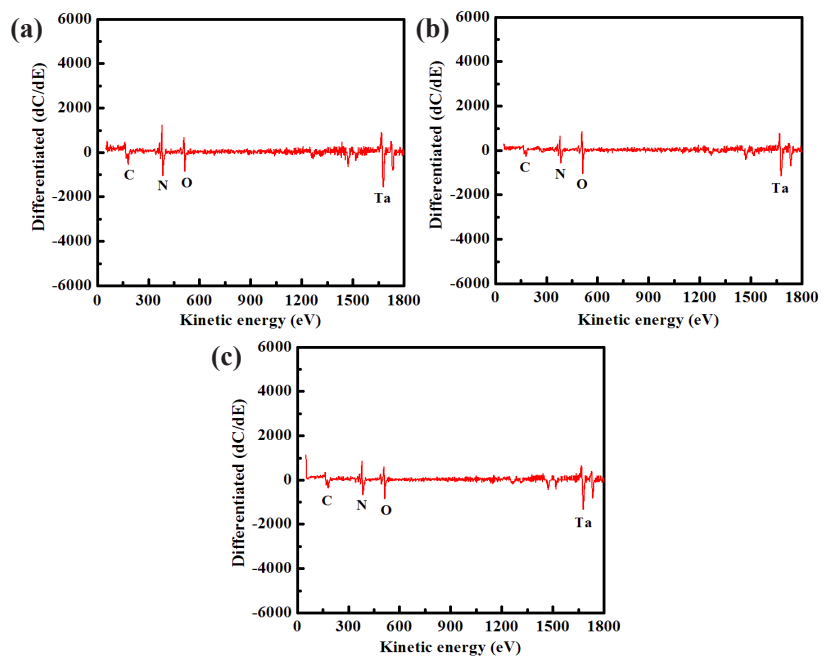

Fig. 8. AES surface scan of the etched TaN thin films as a function of etch chemistry (a) As-deposited, (b) $\mathrm{BCl}_{3} / \mathrm{Cl}_{2} / \mathrm{Ar}$, and (c) $\mathrm{O}_{2} / \mathrm{BCl}_{3} / \mathrm{Cl}_{2} /$ Ar.

\section{CONCLUSIONS}

The etching characteristics of the TaN thin film were investigated in $\mathrm{O}_{2} / \mathrm{BCl}_{3} / \mathrm{Cl}_{2} / \mathrm{Ar}$ plasma. The maximum etch rate of the TaN thin film was $172.7 \mathrm{~nm} / \mathrm{min}$ in the $\mathrm{O}_{2} / \mathrm{BCl}_{3} / \mathrm{Cl}_{2} / \mathrm{Ar}$ (=3:2:18:10) gas mixture. As the $\mathrm{O}_{2}$ fraction in the $\mathrm{O}_{2} / \mathrm{BCl}_{3} / \mathrm{Cl}_{2} /$ Ar plasma was increased from 0 to $3 \mathrm{sccm}$, the etch rate of TaN thin film increased. In addition, the passivation layer formation on the sidewall also increased due to a small amount of $\mathrm{O}_{2}$. However, the etch rate of the TaN thin film decreased with the further addition of $\mathrm{O}_{2}$ gas. The chemical states of the etched TaN thin films were investigated using XPS. The etching mechanism of the TaN thin film can be explained as follows: Ta interacted with the $\mathrm{Cl}$ radicals in the $\mathrm{Cl}_{2}$ containing plasmas, but remained at the surface due to the low volatility of Ta- $\mathrm{Cl}_{x}$, which could be effectively removed with the help of ion bombardment.

\section{REFERENCES}

[1] G. D. Wilk, E. M. Wallace, and J. M. Anthony, J. Appl. Phys. 89, 5243 (2001).

[2] T. Kitagawa, K. Nakamura, K. Osari, K. Takahashi, K. Ono, M. Oosawa, S. Hasaka, and M. Inoue, Jpn. J. Appl. Phys. 45, L297 (2006).

[3] A. I. Kingon, J. I. Maria, and S. K. Streiffer, Nature. 406, 1032 (2000).

[4] H. Shimada, and K. Maruyama, Jpn. J. Appl. Phys. 43, 1768 (2004).

[5] A. L. Gouil, O. Joubert, G. Cunge, T. Chevolleau, L. Vallier, B. Chenevier, and I. Mitko, J. Vac. Sci. Technol. B 25, 767 (2007).

[6] R. Ramos, G. Cunge, and O. Joubert, J. Vac. Sci. Technol. B 26, 181 (2008).

[7] Q. Xie, X. P. Qu, J. J. Tan, Y. L. Jiang, M. Zhou, T. Chen, and G. P. Ru, Appl. Surf. Sci. 253, 1666 (2006).

[8] A. Furuya, E. Soda, M. Shimada, and S Ogawa, Jpn. J. Appl. Phys. 44, 7430 (2005)

[9] M. S. Jo, S. H. Kim, J. M. Lee, S. J. Jung, and J. B. Park, Appl. Phys. Lett. 96, 142110 (2010).

[10] V. Bliznetsov, r. kumar, L. K. Bera, L. W. Yip, A. du, and T. E. Hui, Thin Solid Films 504, 140 (2006)

[11] J. H. Ko, D. Y. Kim, M. S. Park, N. E. Lee, S. S. Lee, J. H. Ahn, and H. 
S. Mok, J. Vac. Sci. Technol. A 25, 990 (2007).

[12] V. Bliznetsov, R. Kumar, L. K. Bera, L. W. Yip, A. Du, and T. E. Hui, Thin Solid Films 504, 140 (2006).

[13] T. Kitagawa, K. Nakamura, K. Osari, K. Takahashi, K. Ono, M. Oosawa, S. Hasaka, and M. Inoue, Jap. J. appl. Phys. 45, L297 (2006)

[14] J. C. Woo, D. S. Um, and C. I. Kim, Thin Solid Fimls 518, 2905 (2010).

[15] G. H. Kim, K. T. Kim, D. P. Kim, and C. I. Kim, Thin Solid Films 475, 86 (2005).

[16] J. Chen, W. J. Yoo, Z. Y. Tan, Y. Wang, and D. S. H. Chan, J. Vac. Sci. Technol. A 22, 1552 (2004).

[17] J. Tonotani, T. Iwamoto, F. Sato, K. Hattori, S. Ohmi, and H. Iwai, J. Vac. Sci. Technol. B 21, 2163 (2003).

[18] W. S. Hwang, J. Chen, W. J. Yoo, and V. Bliznetsov, J. Vac. Sci. Technol. A 23, 964 (2005).

[19] G. H. Kim, C. I. Kim, and A. M. Efremov, Vacuum 79, 231 (2005)
[20] A. M. Efremov, D. P. Kim, C. I. Kim, Thin Solid Films 435, 83 (2003)

[21] H. K. Kim, J. W. Bae, T. K. Kim, K. K. Kim, T. Y. Seong, and I. Adesida, J. Vac. Sci. Technol. B 21, 1273 (2003).

[22] H. Helot, T. Chevolleau, L. Vallier, O. Joubert, E. Blanquet, A. Pisch, P. Mangiagalli, and T. Lill, J. Vac. Sci. Technol. A 24, 30 (2006).

[23] M. H. Shin, S. W. Na, N. E. Lee, and J. H. Ahn, Thin Solid Films 506-507, 230 (2006)

[24] B. H. Lee, K. Kang, W. J. Qi, R. Nich, Y. Jem, K. Onishi, and J. C. Lee, Tech. Dig. Int. Electron Devices Meet. 149, 133 (1999).

[25] C. N. Kirchner, K. H. Hallmeier, R. Szargan, T. Raschke, C. Radehaus, and G. Wittstock, Electroanalysis 19, 1023 (2007).

[26] S. H. N. Lim, D. G. McCulloch, M. M. M. Bilek, D. R. McKenzie, J. Plessis, M. V. Swain, and R. Wuhrer, Surf. Coat. Technol. 201, 396 (2006). 